\title{
Fibrinogen concentrate as first-line hemostatic treatment for the management of bleeding in complex cardiac surgery
}

\author{
Antonio Miceli, MD, PhD, ${ }^{a}$ Marco Ranucci, MD, FESC, ${ }^{\mathrm{b}}$ and Mattia Glauber, $\mathrm{MD}^{\mathrm{a}}$
}

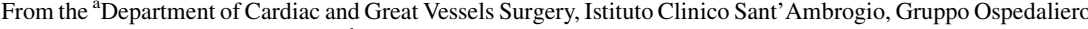
San Donato, Milan, Italy; and the ${ }^{\mathrm{b}}$ Department of Cardiothoracic-Vascular Anesthesia and Intensive Care Unit, IRCCS Policlinico San Donato, Milan, Italy.

Disclosures: Authors have nothing to disclose with regard to commercial support.

Received for publication Sept 3, 2015; accepted for publication Sept 3, 2015; available ahead of print Oct 12, 2015.

Address for reprints: Antonio Miceli, MD, PhD, Department of Cardiac and Great Vessels Surgery, Istituto Clinico Sant'Ambrogio, Gruppo Ospedaliero San Donato, Via Faravelli 16, 20149 Milan, Italy (E-mail: antoniomiceli79@alice.it).

J Thorac Cardiovasc Surg 2016;151:383-4

$0022-5223 / \$ 36.00$

Copyright (C) 2016 by The American Association for Thoracic Surgery

http://dx.doi.org/10.1016/j.jtcvs.2015.09.023
}

Perioperative coagulopathy is a frequent complication after complex aortic arch surgery. In this setting, prolonged extracorporeal circulation, deep hypothermic circulatory arrest, and volume replacement therapy induce a significant impairment of the coagulation system, including platelet dysfunction and hyperfibrinolysis, which if not addressed leads to excessive bleeding, increased need for transfusions, and ischemic complications. These events will finally exert a negative impact on mortality, morbidity, and costs.

Conventionally, the use of fresh-frozen plasma, and cryoprecipitate is the first line in standard care for replacement of coagulation factors in presence of massive bleeding; however, large doses of fresh-frozen plasma are required, and this has often been associated with volume overload, acute lung injury, and nosocomial infections. ${ }^{2}$ The use of point-of-care coagulation tests has been proposed better to elucidate the nature of the bleeding process (deficiency of coagulation factors or fibrinogen, thrombocytopenia, platelet dysfunction, and others) and to tailor the therapeutic approach, therefore minimizing blood product transfusion.

Fibrinogen is an essential component for platelet aggregation and clot formation and plays an important role in achieving and maintaining the hemostatic process. During major cardiac bleeding, fibrinogen is the first coagulation factor to fall to critically low levels; in this setting, fibrinogen supplementation may play an important key role in improving clotting function and reducing perioperative bleeding. ${ }^{2,4}$ In many European countries, the use of fibrinogen concentrate is currently considered the standard of care for acquired bleeding as a result of low fibrinogen levels; conversely, in the Unite Kingdom and the United States, fibrinogen concentrate is only approved at a dosage of $70 \mathrm{mg} / \mathrm{kg}$ for the treatment of congenital fibrinogen deficiency.

In this issue of the Journal, Hanna and colleagues ${ }^{5}$ add evidence that administration of human fibrinogen

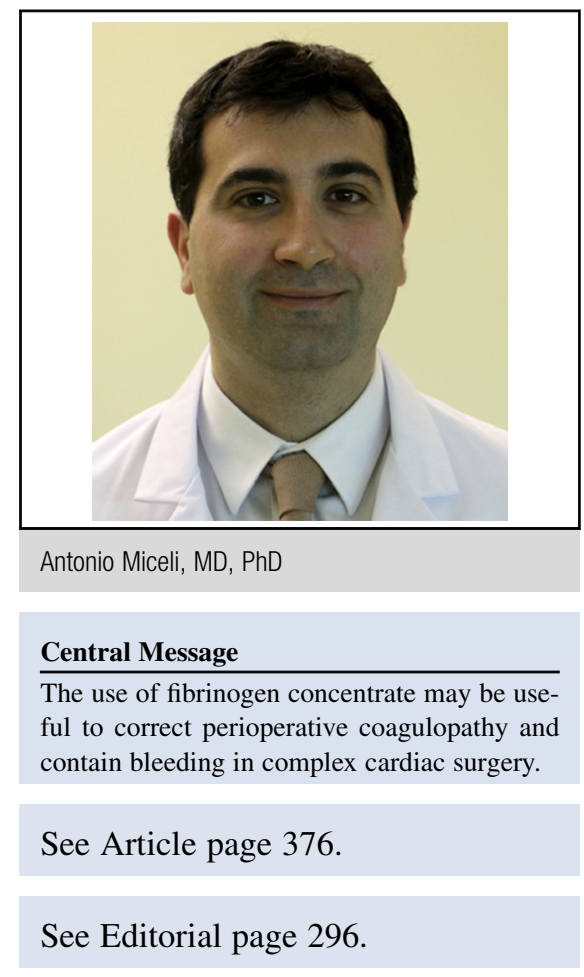

concentrate is safe and effective in raising the serum fibrinogen to normal levels, generating the hypothesis that it may be a useful hemostatic adjunct during complex aortic surgery requiring deep hypothermic circulatory arrest. In this prospective pilot study, 22 patients undergoing aortic surgery and deep hypothermic circulatory arrest received the US Food and Drug Administration-approved dose ( $70 \mathrm{mg} / \mathrm{kg}$ ) of human fibrinogen concentrate at the time of separation from cardiopulmonary bypass. Interestingly, fibrinogen dropped by $25 \%$ from baseline levels just before separation from cardiopulmonary bypass but rapidly increased by $100 \mathrm{mg} / \mathrm{dL} 10$ minutes after the administration of fibrinogen concentrate, returning to normal baseline or greater values. No thromboembolic complications were observed. Despite these results, $90 \%$ of patients still received blood product transfusions, highlighting that bleeding after complex aortic surgery is multifactorial and is related to additional intraoperative factors, such as platelet dysfunction, hemodilution, hypothermia, hypocalcemia, metabolic acidosis, heparin administration, and consumption of other coagulation factors. ${ }^{6}$ Of notice, no point-of-care coagulation test-based algorithm was applied in this study, and the lack of a control group does not allow 
evaluation of the potential benefit of receiving human fibrinogen concentrate in reducing perioperative bleeding and transfusions. Conversely, several randomized, doubleblind, placebo-controlled trials of fibrinogen concentrate supplementation during major aortic surgery or complex cardiac operations have concluded that fibrinogen concentrate is more effective than placebo in postoperative bleeding, leading to a significant reduction in allogenic blood product transfusion. ${ }^{7-9}$ These studies, however, included coagulation point-of-care tests to guide fibrinogen concentrate administration and other therapeutic maneuvers. In that setting, fibrinogen concentrate was more effective than 1 cycle of fresh-frozen plasma and platelets and at least as effective as 2 cycles of fresh-frozen plasma and platelets in controlling coagulopathic bleeding. ${ }^{8}$

Despite these promising results, there is still no consensus regarding (1) the value of postoperative fibrinogen concentration that should trigger a fibrinogen supplementation, (2) the exact dose of fibrinogen concentrate, and (3) the target value to be achieved. Unfortunately, the study of Hanna and colleagues ${ }^{5}$ does not address any of these points. Historically, fibrinogen supplementation has been recommended for values less than $100 \mathrm{mg} / \mathrm{dL}$ (the normal plasma concentration ranges between 200 and $450 \mathrm{mg} / \mathrm{dL}$ ), although higher levels have been suggested $(250 \mathrm{mg} / \mathrm{dL}) .{ }^{10}$ The appropriate dose of fibrinogen concentrate might be determined by a point-of-care test such thromboelastometry or thromboelastography; however, these tests are not available in all the cardiac surgery institutions. A previous study estimated that a $70-\mathrm{kg}$ patient would require a mean dose of $780 \mathrm{mg} / \mathrm{dL}$ of fibrinogen concentrate to avoid intraoperative transfusion of freshfrozen plasma and platelet concentrate to treat major aortic surgery bleeding. ${ }^{11}$

In conclusion, there is evidence that fibrinogen concentrate supplementation may be useful to contain postoperative bleeding in aortic surgery ${ }^{4,5,8}$ and major cardiac surgery ${ }^{7}$; however, the trigger value, dose, and target value for fibrinogen concentrate supplementation are still to be defined. In addition, it is likely that this approach should be guided by an appropriate algorithm that includes coagulation point-of-care tests to "tailor" an appropriate hemostatic treatment.

\section{References}

1. Achneck HE, Rizzo JA, Tranquilli M, Elefteriades JA. Safety of thoracic aortic surgery in the present era. Ann Thorac Surg. 2007;84:1180-5; discussion 1185.

2. Ranucci M. Fibrinogen supplementation in cardiac surgery: where are we now and where are we going? J Cardiothorac Vasc Anesth. 2013;27:1-4.

3. Ranucci M, Aronson S, Dietrich W, Dyke CM, Hofmann A, Karkuti K, et al. Patient blood management during cardiac surgery: do we have enough evidence for clinical practice? J Thoracic Cardiovasc Surg. 2011;142:249. e1-32.

4. Rahe-Meyer N. Fibrinogen concentrate in the treatment of severe bleeding after aortic aneurysm graft surgery. Thromb Res. 2011;128(Suppl 1):S17-9.

5. Hanna JM, Keenan JE, Wang H, Andersen ND, Gaca JG, Lombard FW, et al. Use of human fibrinogen concentrate during proximal aortic reconstruction with deep hypothermic circulatory arrest. J Thorac Cardiovasc Surg. 2016;151:376-82.

6. Bojar RM. Mediastinal bleeding. In: Manual of perioperative care in adult cardiac surgery. 5th ed. Hoboken: Blackwell Publishing; 2011:347-81.

7. Ranucci M, Baryshnikova E, Crapelli GB, Rahe-Meyer N, Menicanti L, Frigiola A; Surgical Clinical Outcome REsearch (SCORE) Group. Randomize, double-blinded, placebo-controlled trial of fibrinogen concentrate supplementation after complex cardiac surgery. J Am Heart Association. 2015;4:e002066.

8. Rahe-Meyer N, Hanke A, Schmidt DS, Hagl C, Pichlmaier M. Fibrinogen concentrate reduces intraoperative bleeding when used as first line hemostatic therapy during major aortic replacement surgery: results from a randomized, placebo-controlled trial. J Thoracic Cardiovascular Surg. 2013;145(3 Suppl): S178-85.

9. Solomon C, Hagl C, Rahe-Meyer N. Time course of hemostatic effects of fibrinogen concentrate administration in aortic surgery. Br J Anaesth. 2013;110: 947-56.

10. Ranucci M, Jeppsson A, Baryshnikova E. Pre-operative fibrinogen supplementation in cardiac surgery patients: an evaluation of different trigger values. Acta Anaesthesiol Scand. 2015;59:427-33.

11. Rahe-Meyer N, Solomon C, Winterhalter M, Piepenbrock S, Tanaka K, Haverich A, et al. Thromboelastometry-guided administration of fibrinogen concentrate for the treatment of excessive intraoperative bleeding in thoracoabdominal aortic aneurysm surgery. J Thoracic Cardiovasc Surg. 2009;138:694-702. 